\title{
Effect of rotary tiller blades on soil disintegration
}

\section{A.N. Rajesh, B. Shridar and D. Manohar Jesudas}

Received : 17.01.2018; Revised : 11.02.2018; Accepted : 20.02.2018

See end of the Paper for authors' affiliation

Correspondence to :

\section{A.N. Rajesh}

Agricultural Machinery Research Centre, Tamil Nadu Agricultural University, Coimbatore (T.N.) India Email : anrajeshtcr@gmail.com
- ABSTRACT : Weeding between the crop rows is the most important practice to enhance the yield. The blade shape, forward speed and rotary speed are the key parameters come to decision for pulverizing soil condition. Thus, this study was aimed to determine the furrow formation characteristics of two blades used in rotary weeder. The experiments were carried out in indoor laboratory soil bin condition. The moisture content of the clay soil was 12 to 13 per cent and penetration resistance was $590 \mathrm{kPa}$. The rotary shaft was attached with a flange with four blades and the rotor diameter was $250 \mathrm{~mm}$. The highest furrow backfill of 76.26 per cent was reported by the straight blade at lower forward speed. The furrow backfill has decreased with increase in both forward speed and rotary speed of two blades. Maximum ratio of soil breaking of 92.86 per cent was obtained at a rotary speed of $300 \mathrm{rpm}$ by the straight blade. Ratio of soil breaking has decreased with increase in forward speed and increased with increase in rotary speed. Based on the results rotary weeding technique with straight blade was found to be effective.

- KEY WORDS : Rotary blade, Rotary weeder, Soil bin, Furrow backfill, Soil breaking

- HOW TO CITE THIS PAPER : Rajesh, A.N., Shridar, B. and Jesudas, D. Manohar (2018). Effect of rotary tiller blades on soil disintegration. Internat. J. Agric. Engg., 11(1) : 73-78, DOI: 10.15740/ HAS/IJAE/11.1/73-78. 